\title{
Drying behavior, diffusion modeling of cuminum cyminum $L$. undergoing microwave-assisted fluidized bed drying
}

Babaki, A.; Askari, G. ; Emamdjomeh, Z.

Transport Phenomena Laboratory (TPL), Departmatn of Food Science and Technology, College of Agriculture and Natural Resources, University of Tehran, Karaj, Iran

*E-mail of the corresponding author: iraskari@ut.ac.ir

\begin{abstract}
In order to conserve cuminum cyminum L. during long storage periods, the drying kinetics of this seed undergoing microwave-assisted fluidized bed dryer at various microwave output power (300, 600 and 900w), air velocity $(10,15$ and $20 \mathrm{~m} / \mathrm{s})$ and air temperatures $\left(45,55\right.$ and $\left.65^{\circ} \mathrm{c}\right)$ were studied. The main aim of this research is developing a mathematical model of mass transfer to investigate the microwave-assisted fluidized bed drying of cuminum cyminum L. seed. In this paper, we tried to discover a good model to evaluate moisture effective diffusivity $\left(D_{\text {eff }}\right)$.
\end{abstract}

Keywords: cuminum cyminum L, microwave-assisted drying, mathematical modeling, 


\section{Introduction}

Cumin (cuminum cyminum) is one of the functional and valuable spices in food preparations. It is popular for its strong, sweet aroma and slightly bitter taste. In addition to its seasoning application, its pharmaceutical properties are influential. Cumin name originally derived from the Greek word "kyminon”.Several functional benefits of cumin consumption are: hypolipidemic, digestion stimulating, antispasmodic, wound-healing, anti-microbial, anti-oxidant, carminative and anti-inflammatory agent. Ground cumin is commonly used in Iranian culinary and confectionary, meaty Moroccan foods and classic German foods [1-4]. Iran was among the countries that devote themselves to the large surface area of the land was cultivated cumin, and its production in this area was about 12,000 tons per year [5].

Drying is frequently used in agricultural and food processing. Essential oils are important part in herbs, due to thir importance and thermal sensitivity they have to dried at moderate thermal condition and short time [6]. Fluidized bed drier has high thermal efficiency in solid drying. Direct intact between samples and heating medium leads to simultaneous as well as rapid heat, and mass transfer. However conductive heat transfer from surface to the inside of materials is still slow. This may be solved by using microwave assisted fluidized bed drier. This article focuses on mathematical modeling of cumin as an assumed cylindrical shaped seed, dried undergoing various treatment in order to assess water loss procedure.

\section{Materials and Methods}

\subsection{Dying procedure}

Cumin seeds were purchased from local grocery in Karaj city (north of Iran) in October. At first they were cleaned manually then got uniformed by a sieve having 20 meshes. Predetermined amount of water added to a certain quantity of samples obtain determained moisture content. A pilot-scale microwave- assisted fluidized bed dryer was applied for dehydration experiments. For each test, $50 \mathrm{~g}$ cumin seeds slightly poured into drying dish to make them uniform. The drying tests were conducted at three levels of power $(300,600$, $900 \mathrm{w})$, air temperature $\left(45,55,65^{\circ} \mathrm{C}\right)$ and air velocity $(5,7.5,10 \mathrm{~m} / \mathrm{s})$ to reach a specific moisture content $(5.66 \%$ d.b). $\mathrm{V}=4.5 \mathrm{~m} / \mathrm{s}$ is experimentally determined as the minimum fluidization velocity. Moisture ratio was calculated based on following equation [7]:

$$
M R=\frac{M-M_{e}}{M_{0}-M_{e}}
$$


Babaki, A.; Askari, G.; Emamdjomeh, Z.

Table.1 independent variables

\begin{tabular}{llllll}
\hline Factor & Name & Units & Minimum & Maximum & Mean \\
\hline $\mathrm{A}=\mathrm{X}_{1}$ & temperature & ${ }^{\circ} \mathrm{c}$ & 45 & 65 & 55 \\
$\mathrm{~B}=\mathrm{X}_{2}$ & Microwave power & $\mathrm{w}$ & 300 & 900 & 600 \\
$\mathrm{C}=\mathrm{X}_{3}$ & Air velocity & $\mathrm{m} / \mathrm{s}$ & 10 & 20 & 15 \\
\hline
\end{tabular}

\subsection{Mathematical modelling and Moisture diffusivity determination}

In order to facilitate the calculation of the effective diffusion coefficient, a new method was designed and developed. In this case, the oval shaped cumin seed was considered as a cylinder with the surface are a similar to the elliptical cumin seed. So firstly, side surface area of elliptical cumin particles were calculated by circulating equation (2) around horizontal “a” axis (fig 1) [8].

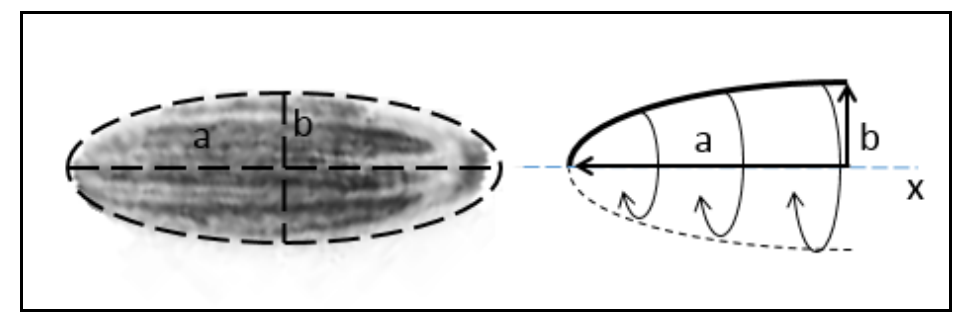

Figure 1. Cumin seed scheme for the model geometry

$s=2 \pi \int_{0}^{a} y \sqrt{1+y^{\prime 2}} d x$

For an entire ellipsoid:

$s=4 \pi \int_{0}^{a} y \sqrt{1+y^{\prime 2}} d x$

Then via equating ellipsoid surface area with cylinder surface area, the radius $\left(\mathrm{r}_{\mathrm{c}}\right)$ was calculated from following equation:

$2 \pi r_{c}(2 a)+2 \pi r_{c}^{2}=2 \pi a b\left[\frac{\operatorname{Arcsin} \sqrt{a^{2}-b^{2}}}{\frac{\sqrt{a^{2}-b^{2}}}{a}}+\frac{b}{a}\right]$

Large radius of 20 seeds were measured by digital caliper with an accuracy of $0.01 \mathrm{~mm}$ (Mitutoyo, Japan) and their average value was considered as' a' factor in above equation. 
Water loss process during solid dehydration consists of several complex mechanisms. With regard to this fact, Fick's second low effective diffusivity have been considered as a combination of mentioned mechanisms $[6,9]$.

$\frac{\partial M}{\partial t}=\operatorname{Div}\left[D_{e f f}(\operatorname{grad} M)\right]$

Initial and boundary conditions of eq (9) with ignoring shrinkage are defined as follow:

$t=0, \quad M=M_{0}$

$t>0, \quad r=0, \quad \frac{\partial M}{\partial r}=0$

$t>0, \quad r=r_{c} \quad$ and $\quad z=L, \quad M=M_{\theta}$

Fickian equation solution could be simplified to infinite slab and cylinder and finite cylinder by assuming the first part in series expansion of their equation respectively [9, 10]:

$M R_{i s}=\frac{M-M_{e}}{M_{0}-M_{e}}=\frac{8}{\pi^{2}} \exp \left(-B_{i s} t\right)$

$M R_{i c}=\frac{M-M_{e}}{M_{0}-M_{e}}=\frac{4}{\beta_{1}^{2}} \exp \left(-B_{i c} t\right)$

$M R_{f c}=\frac{M-M_{e}}{M_{0}-M_{e}}=\frac{32}{\pi^{2} \beta_{1}^{2}} \exp \left(-B_{f c} t\right)$

Wherein:

$B_{i s}=\pi^{2} D_{s l a b} / L^{2}$

$B_{\text {ic }}=\beta_{1}^{2} D_{\text {cyl }} / r_{c}^{2}$

$B_{f c}=\frac{\pi^{2} D_{s l a b}}{L^{2}}+\frac{\beta_{1}^{2} D_{c y l}}{r_{c}^{2}}$

Where $D_{\text {slab }}$ and $D_{\text {cyl }}$ are the moisture diffusivities that were assumed equal. $L$ and $r_{c}$ are the real length of cumin seed and the computed radius of the cylinder in eq (4) in the order given and $\beta_{1}=2.4048$ was obtained from the tables of the first kind of zero order Bessel function $\left(\mathrm{J}_{\mathrm{o}}\left(\mathrm{a} \alpha_{\mathrm{n}}\right)=0\right)$ [10]. The constant $\mathrm{B}$ can be determined by plotting $\ln (\mathrm{MR})$ against drying time (s) for any experiment. 


\section{Results and discussion}

\subsection{Drying kinetic}

The Cumin samples ( $\mathrm{M}_{0}=35.44 \%$ (d.b)) were dried to $\mathrm{M}=5.66 \%$ (d.b). Central composite design (CCRD) with three indepenfdent variables includes microwave output power, air temperature, air velocity, on three levels, at the central point plan was applied. As expected, moisture content kept decreasing by increasing drying time, temperature and microwave power, (fig. $2 \mathrm{a}$ and b). In table.2 drying rate values based on different test conditions, are provided. During microwave heating, water components due to their higher dielectric loss factor, absorb a greater amount of microwave energy and reach the boiling temperature, consequently the pressure in the interior of the material develops, this causes the moisture to move from the inside to the surface [11, 12]. At first, internal heating caused by microwave, moves liquid water towards surface of samples (Darcy's law). With the progress of the drying procedure, internal moisture supply is not able to provide the surface evaporation process. Thus, after this stage, dehydration is driven by vapor diffusion and Darcy's flow [13]. As can be seen in fig.2c, air flow rate increase to more than minimum fluidization velocity $(15 \mathrm{~m} / \mathrm{s})$ has no effect on drying rate and drying time, because increasing air velocity, increases bed pressure drop.
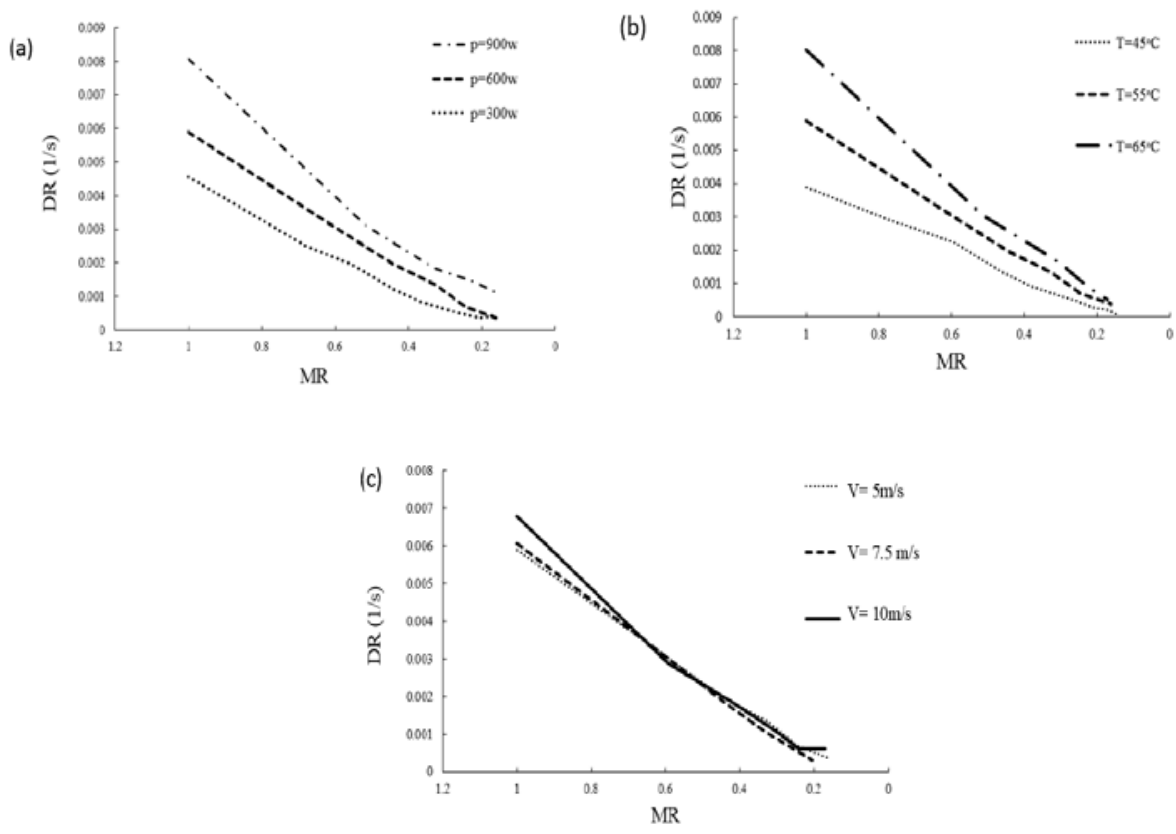

Fig. 2 effect of microwave power (a: $v=15 \mathrm{~m} / \mathrm{s}, \mathrm{T}=55^{\circ} \mathrm{C}$ ) air temperature ( $b: p=600 w, v=15 \mathrm{~m} / \mathrm{s}$ ) and air velocity $\left(c: p=600 w, T=55^{\circ} \mathrm{C}\right)$ on drying rate. 
From a certain speed onwards, the amount of pressure drop has been stabilized and there isn't much change in it. Constant pressure drop is due to change in the nature of the bed particles from fixed state to fluid state, so from this point on, pressure drop will be same as liquid static pressure drop and depend on height of bed [14].

\subsection{Effective moisture diffusivity and activation energy}

Effective moisture diffusivity: Radius value obtained from eq (8) is $0.373 \mathrm{~mm}$. by using slope of fig. 3 graphs and putting them in eq (15), effective moisture diffusivity under various test conditions was determined. The measured $D_{\text {eff }}$ values for cumin seeds are presented in table.2.

As shown, $D_{\text {eff }}$ values were ranged from $3.820 \times 10^{-11}$ to $2.746 \times 10^{-10} \mathrm{~m}^{2} / \mathrm{s}$. This result is in accordance with results obtained from most food stuffs $\left(10^{-12}-10^{-8} \mathrm{~m}^{2} / \mathrm{s}\right)[15,16]$. It is observed that the highest amount of $D_{\text {eff }}$ is related to $\mathrm{P}=900 \mathrm{w}$ and $\mathrm{T}=65^{\circ} \mathrm{C}$ and the lowest amount of $D_{\text {eff }}$ is related to $\mathrm{P}=300 \mathrm{w}$ and $\mathrm{T}=45^{\circ} \mathrm{C}$. It was observed that increasing the temperature of drying air and microwave power, increased the effective moisture diffusivity.
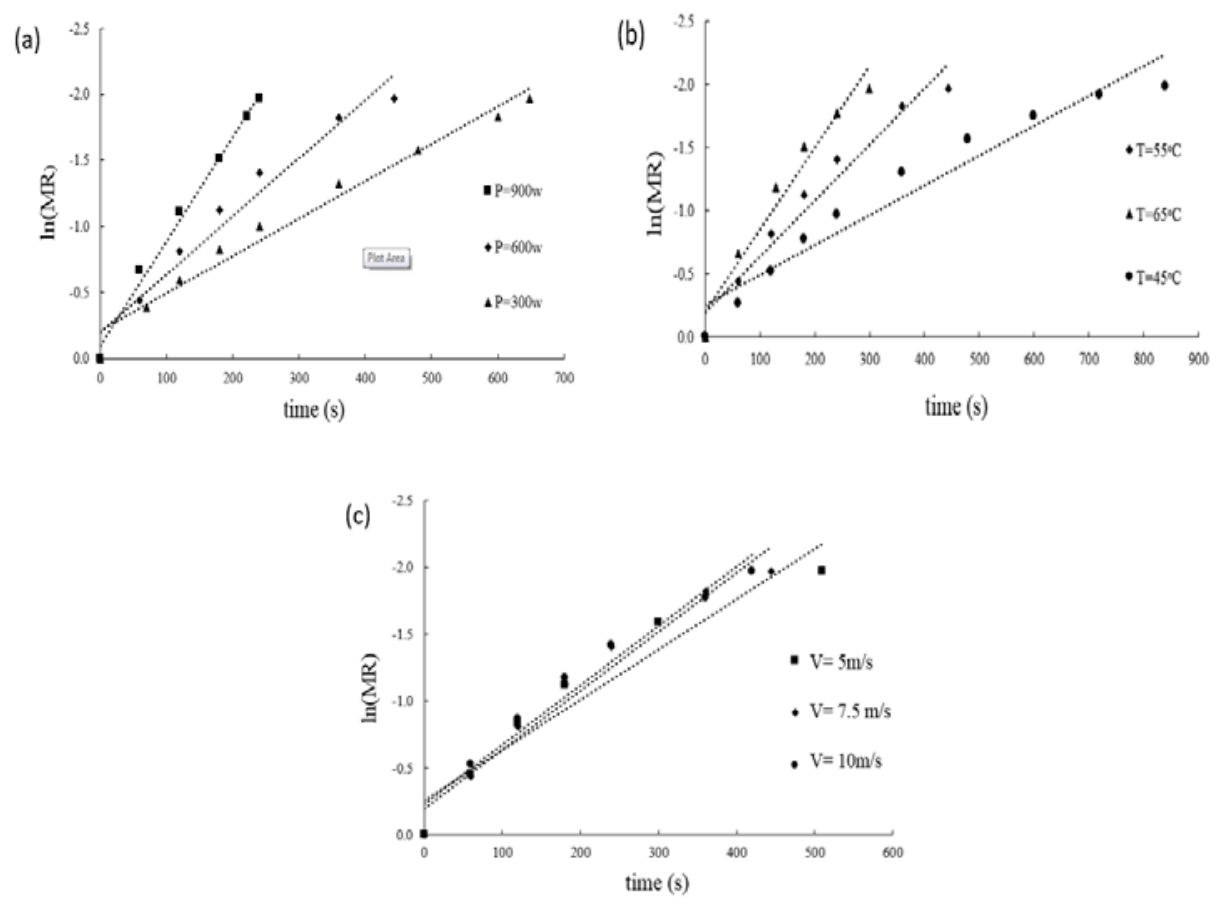

Fig. 2 effect of microwave power ( $a: v=15 \mathrm{~m} / \mathrm{s}, \mathrm{T}=55^{\circ} \mathrm{C}$ ) air temperature (b: $p=600 \mathrm{w}, v=15 \mathrm{~m} / \mathrm{s}$ ) and air velocity $\left(c: p=600 w, T=55^{\circ} \mathrm{C}\right)$ on drying rate. 
These results are in agreement with the results of microwave drying of pandanus leaves [17] and hot-air and microwave drying of pineapple [15] and fluidized bed drying of canola [16]. There is no significant effect of various velocity of drying air on slope of fig.3c and consequently on $D_{\text {eff }}$ was observed. As mentioned earlier, this action is due to the mechanism of pressure drop during drying procedure.

Table. 2 Amounts of DR, RMSE, SSE and Deff of cumin seed undergoing different drying condition

\begin{tabular}{lcclll}
\hline $\begin{array}{l}\text { Microwave } \\
\text { power }(\mathrm{w})\end{array}$ & $\begin{array}{l}\text { Air temperature } \\
\left({ }^{\circ} \mathrm{C}\right)\end{array}$ & $\begin{array}{l}\text { Air velocity } \\
(\mathrm{m} / \mathrm{s})\end{array}$ & $\begin{array}{l}\text { Drying rate } \\
(1 / \mathrm{s})\end{array}$ & $\begin{array}{l}\mathrm{D}_{\text {eff }}\left(\mathrm{m}^{2} / \mathrm{s}\right) \\
\times 10^{-10}\end{array}$ & $\mathrm{R}^{2}$ \\
\hline 300.00 & 65.00 & 10.00 & 0.004 & 0.883 & 0.9813 \\
900.00 & 45.00 & 10.00 & 0.005 & 1.074 & 0.8936 \\
300.00 & 65.00 & 20.00 & 0.004 & 0.955 & 0.891 \\
300.00 & 45.00 & 10.00 & 0.002 & 0.382 & 0.9661 \\
600.00 & 55.00 & 20.00 & 0.005 & 1.051 & 0.9587 \\
900.00 & 65.00 & 20.00 & 0.011 & 2.746 & 0.9694 \\
900.00 & 55.00 & 15.00 & 0.009 & 1.886 & 0.9918 \\
300.00 & 45.00 & 20.00 & 0.002 & 0.405 & 0.9581 \\
900.00 & 65.00 & 10.00 & 0.01 & 2.459 & 0.9997 \\
600.00 & 65.00 & 15.00 & 0.006 & 1.552 & 0.9572 \\
300.00 & 55.00 & 15.00 & 0.0035 & 0.668 & 0.9745 \\
900.00 & 45.00 & 20.00 & 0.005 & 1.218 & 0.9342 \\
600.00 & 55.00 & 15.00 & 0.005 & 1.062 & 0.9601 \\
600.00 & 55.00 & 10.00 & 0.004 & 0.883 & 0.924 \\
600.00 & 45.00 & 15.00 & 0.002 & 0.573 & 0.9429 \\
\hline
\end{tabular}

\section{Conclusion}

Drying specifications of cumin seeds were assessed during microwave-assisted fluidized bed drying at various levels of air temperature, microwave power and air velocity. The entire dehydration process occurred in the falling rate period. Applying higher values of microwave output power, air temperature and air velocity enhanced drying rate and $D_{\text {eff. }}$ Although increased to more than the minimum fluidization velocity of air flow rate, did not show a significant impact on drying rate. Simulation elliptical cumin seed to cylinder, to obtain $D_{\text {eff }}$ and $\mathrm{E}_{\mathrm{a}}$ offered good results with high amount of $\mathrm{R}^{2}$. Usage of RSM ensured that the selected factors had significant effect on responses and on each other as well. Increment in air temperature and air velocity used in this study, caused decrement in $\mathrm{E}_{\mathrm{C}}$ value but microwave power affected on $E_{C}$ in increasing manner. And finally optimum condition obtained by RSM offered that operating minimum fluidization velocity, maximum value of microwave power and air temperature, maximize drying rate value and minimize energy consumption value. 


\section{References}

[1] Aliakbarlu, J., S.K; Sadaghiani; S. Mohammadi, Comparative evaluation of antioxidant and anti food-borne bacterial activities of essential oils from some spices commonly consumed in Iran. Food Science and Biotechnology, 2013. 22(6): p. 1487-1493.

[2] Amin, G.; Cumin. Vol. 111. 2012, Tehran: Tehran University of Medical Sciences Press.

[3] Zomorodian, A; M. Moradi, Mathematical modeling of forced convection thin layer solar drying for Cuminum cyminum. Journal of Agricultural Science and Technology, 2010. 12: p. 401-408.

[4] Rai, N., et al., A Monographic Profile on Quality Specifications for a Herbal Drug and Spice of Commerce-Cuminum cyminum L. International Journal of Advanced Herbal Science and Technology, 2012. 1(1): p. pp. 1-12.

[5] Al-Snafi, A.E.; The pharmacological activities of Cuminum cyminum-A review. IOSR Journal of Pharmacy, 2016. 6(6): p. 46-65.

[6] Torki-Harchegani, M., et al., Dehydration behaviour, mathematical modelling, energy efficiency and essential oil yield of peppermint leaves undergoing microwave and hot air treatments. Renewable and Sustainable Energy Reviews, 2016. 58: p. 407-418.

[7] Askari, G.; Z. Emam-Djomeh.; S. Mousavi.; Heat and mass transfer in apple cubes in a microwave-assisted fluidized bed drier. Food and Bioproducts Processing, 2013. 91(3): p. 207215.

[8] Piskunov, N.S., Differential and integral calculus. Vol. 2. 1974: Mir.

[9] Souraki, B.A.; D. Mowla, Axial and radial moisture diffusivity in cylindrical fresh green beans in a fluidized bed dryer with energy carrier: Modeling with and without shrinkage. Journal of Food Engineering, 2008. 88(1): p. 9-19.

[10] Crank, J., The mathematics of diffusion. 1979: Oxford university press.

[11] Mahendran, R.; G. Jayashree.; K. Alagusundaram. Application of computer vision technique on sorting and grading of fruits and vegetables. J Food Process Technol, 2012. 10: p. 2157-7110.

[12] Rattanadecho, P.; N. Makul, Microwave-assisted drying: A review of the state-of-the-art. Drying Technology, 2016. 34(1): p. 1-38.

[13] Qi, L.-L., et al., Comparison of drying characteristics and quality of shiitake mushrooms (Lentinus edodes) using different drying methods. Drying technology, 2014. 32(15): p. 17511761.

[14] Goksu, E.I.; G. Sumnu.; A. Esin, Effect of microwave on fluidized bed drying of macaroni beads. Journal of Food Engineering, 2005. 66(4): p. 463-468.

[15] Ghasemi, H.; H. Amini; M. Khayat, An experimental study of fluidization of solids particles in a bubbling fluidized bed. Modares Mechanical Engineering, 2015. 14(16).

[16] Gazor, H.R.; A. Mohsenimanesh, Modelling the drying kinetics of canola in fluidised bed dryer. Czech Journal of Food Sciences, 2010. 28(6): p. 531-537.

[17] Rayaguru, K.; W. Routray, Microwave drying kinetics and quality characteristics of aromatic Pandanus amaryllifolius leaves. International Food Research Journal, 2011. 18(3). 